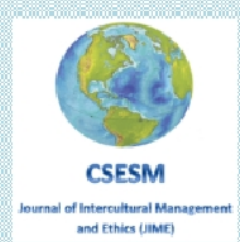

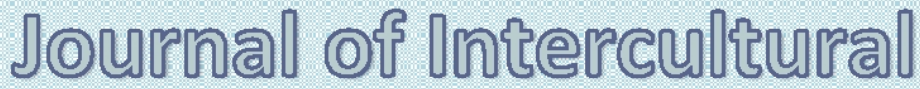

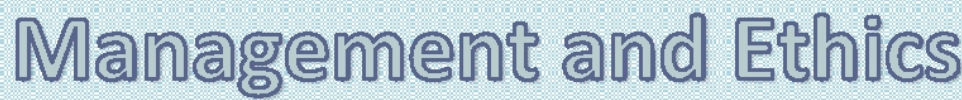

\author{
IOME
}

ISSN 2601 - 5749, ISSN-L 2601 - 5749

\section{published by zy \\ Center for Socio-Economic Studies and Multiculturalism \\ lasi, Romania \\ Waw csesmorg}




\section{Special Editor}

\section{Professor Beatrice Gabriela Ioan, PhD, MD}

Grigore T.Popa University of Medicine and Pharmacy of Iasi, Romania

E-mail: ioanbml@yahoo.com

\section{TABLE OF CONTENT}

Editorial ....

Beatrice Gabriela Ioan

Ethical Approaches on the Mandatory Vaccination in the Pandemic Context (Romania Case)

Andreea-Iulia Someșan, Ion Copoeru

Early Approaches in Management of Sars-Cov-2 Infection 19

Isabela-Ioana Loghin, Adriana-Florina Bahnă, Oana-Manuela Secrieru, Irina-Margareta

Nistor, Irina-Cristina Nicolau, Liviu Jany Prisăcariu, Florin Roșu, Victor Daniel Dorobăţ,

Cristin-Ioan Loghin, Carmen-Mihaela Dorobăț

Giving Birth during the Pandemic. How The Decision to Transform Certain Hospitals In Dedicated Covid-19 Medical Units Impacted Women on Psychological Level

Alexandra Ștefania Nadane

Evangelicalism in Uganda: Implications for Public Health and Bioethics

Sana Loue, Francis Bajunirwe

The Contribution of Ethics to the Development of the Healthcare System

Cornelia Margareta Găşpărel

Iatrogenesis Induced by Risk Reduction in Health Care

Mircea Gelu Buta

Ethical Contributions in Preserving the Dignity of the Terminal Patient

Elena Toader, Andreea Decusara, Mirela Piscuc, Tudor Winsinger

Ethical Aspects of the Institutionalization Process of Children from Outbreaks of

Tuberculosis

Rodica Gramma, Elena Cernăuțeanu, Adriana Paladi

Profession, Vocation, Mission or Work. The Ancient Physician and the Contemporary

Physician-Parallel Lives

Orsolya Horber, K.Zilahi 


\title{
IATROGENESIS INDUCED BY RISK REDUCTION IN HEALTH CARE
}

\begin{abstract}
Mircea Gelu Buta
Faculty of Orthodox Theology, "Babes-Bolyai” University, Cluj-Napoca, Romania

E-mail: butamircea@yahoo.com

Abstract

There are two major currents of thought in science: the reductionist and the holistic, which have also been transposed into medicine. If we understand that the human body is a very complex system, an ecosystem with thousands of components inside and a lot of intertwined and inter-conditioned relationships between them, we will find that the reductionist approach is simply insufficient and will never end. Seeing reality only as a mathematical system develops the paradigm for control and manipulation. The body is thus seen as consisting of mechanical subsystems whose output numbers can be measured by biomarkers and whose risks can be predicted based on inputs. In this situation, health ceases to be based on subjective well-being or ability to work, but is based on how one fits the numerical norms.
\end{abstract}

Keywords: holism, reductionism, quantified self, medicine

\section{Holism and / or reductionism in medicine}

Towards the end of the twentieth century, science was almost exclusively polarized by reductionist thinking to the detriment of holistic thinking. If reductionism helps us to understand the whole by studying its component parts, holism has the central idea that the whole is more than the sum of its components. Medicine, in order to be better studied, has been divided, like other sciences, into several disciplines: pneumology, cardiology, gastroenterology, neurology, psychiatry, gynecology, etc. The notions of body and soul, which make up the human body, make possible the proper functioning of the genome and neurons. But man represents something more than that, he is a person. In other words, the human body is the bearer of a life project. In addition, he is the bearer of a desire for life and experiences that underpins his recognized right to morality (Buta, 2008).

How can you fully help a person who has an affected organ if his disease manifests itself in a systemic context, namely in connection with the functioning of other organs in his body? In addition, the environment is constantly shaping life. We can clearly state that every facet of individuality requires the participation of the environment. In other words, we are both heredity and environment. Nothing is determined exclusively by heredity as nothing is determined exclusively by the environment.

When we make an analysis of the factors that produced the disease, according to the reductionist approach, you come to the conclusion that you need to be simultaneously hematologist, biochemist, microbiologist, geneticist, immunologist, nutritionist, but also biologist, ecologist, computer scientist, specializations that today seem impossible to grasp by the mind of one man. However, life was not created by disciplines, and neither is the human body, nor is it made up of separate organs and processes, which are analyzed in an isolated context. This is a very complex system, an ecosystem with thousands of components inside and myriads of intertwined and interconnected relationships. 
That is why the isolated reductionist approach to the phenomena is insufficient and without an overview we will not be able to see the forest because of the trees.

If we miss something in today's medicine, we probably lost the image of the whole somewhere along the way. So let's go back to the whole and never forget that "the whole is more than the sum of the parts." It is the only way will to get rid of the chronic diseases that grind humanity, but also to heal the planet we live on and to which we have done, consciously or unconsciously, so much harm.

\section{The quantified self}

From the point of view of secular medicine, the thresholds of significance of the pathological, of transition from normal to abnormal are not clearly delimited, not even in the case of somatic suffering and even less in the case of mental suffering, where the boundaries between normal and pathological impose a high degree of fluctuations.

In 1958, the World Health Organization tried to define health as "a perfect state of physical, mental and social well-being." This punctuation, although it has the advantage of influencing mentalities and implementing new ways of approaching health practices, tends to suggest that one cannot be healthy without that "perfect well-being." But we know that people can go through varying degrees of well-being without necessarily being considered sick. Judging by this, it means that health programs should be designed in such a way that each person is brought to a state of physical, mental and social well-being, according to standards, sometimes "foreign" to the way he conceives his life and maybe even against his will.

In recent years, a new idea has begun to emerge, which promises to radically transform medicine: the "quantified self." Initiated by several enthusiasts in "Wired Magazine" (Gary Wolf, Kevin Kelly, 2007) ${ }^{1}$, the theory of "quantified self" (QS), is the application of the scientific method on the self by assessing oneself with a set of indicators (Droge, 2016). The list of parameters we can measure is endless: heart rate, breathing, hours of sleep or even the number of sneezing and coughing during a day. However, not all things in our lives can be measured and not everything that can be measured is important.

The problem with this model lies in its anthropology and worldview. The slogan that the authors of the "Quantified Self" use is "Self-knowledge through numbers". What could that mean? Of course, you can learn things about yourself through numbers, and "body weight" is the handiest parameter. However, self-knowledge has connotations that go beyond everyday facts. On the temple of Apollo in Delphi, was inscribed one of the most proud thoughts "Know thyself" ("Gnothi seauton!"), which entered the cultural consciousness of the world through its cultural and moral significance, transmitting an exhortation related to the spiritual dimension of man. Over time, this ideal has undergone interpretations, being taken over by science, which uses it to measure and record a wide variety of human activities. At the beginning, the ideal was mastered by athletes, on their way to performance. As their goal is explicit, they run faster, weigh less, improve their mobility, acquire skills, monitoring the morpho-functional indicators appears natural. Science, however, did not stop there and opened up possibilities for exploration in areas of life that did not always seem accessible to quantitative methods. If you could track the transient moods and emotions of the "diarists"2 by reading their notebook, today there is "open source software" for random sampling of a person's experience. This feature is already built into measurement tools such as "Happy Factor", a Facebook application that subjects you to a random survey with a text message, to which you respond with a number that ultimately indicates your level of happiness. There are protocols for measuring mental capacity that take less than five minutes and provide data for brain agility. The website "CureTogether" allows users to record a wide range of conditions, symptoms and feelings, and self-tracking 
systems can measure our bodies, movements and minds. In this situation, the natural question that arises is whether we can measure our "narcissism"? There is a psychological test, validated for measuring narcissism, which can be completed in just a few minutes. However, experts argue that the test is not accurate, because when people ask if self-pursuit is narcissistic, they are not asking about clinical narcissism, but about selfishness, narrowness, a withdrawal from social commitment and social generosity, in a selfish world of self.

The purpose of wellness programs is to get to know ourselves through the numbers and thus gain control over our lives. The anthropological problem of this model is his reductionist vision of the human body or as Pope Francis calls it "Technocratic Paradigm", namely a way of seeing the world as a material prepared for control and manipulation, according to the will of the people (Davis \& Gonzalez, 2016), which was also supported by Heidegger in a work published a year after his death (Heidegger, 1977). If the human body is seen as a complex of mechanical subsystems whose output numbers can be measured by biomarkers and whose operational risks can be predicted based on inputs, then health ceases to be based on subjective well-being or activity capacity, but it is based on how someone fits the established numerical rules. This means that we assume our dispositions and ways of engaging the world through sets of common practices. Mechanistic paradigm can be incorporated into a different area of medicine, because few doctors consider the human body as a dead matter, consisting of mechanical subsystems whose risk profiles can be optimized. This vision of the body is included in our social consciousness through daily contact with clinical technologies, such as testing biomarkers or wellness tools that patients use on their own body, a situation in which these subsystems can be modified and optimized at will (Bishop, 2011, pp.411). In other words, to reduce the risks, the body can be modified, from its natural state, to obtain a better number. For example, genes that regulate cholesterol can be removed to maintain the desired value of this parameter.

Of course, it is difficult to escape this form of thinking once it has entered its logic. One thing is for sure, however, there is never an absolute level of risk control, so technologybased interventions and control mechanisms are endless, and such a framework can only discourage and alienate. Even if we have our own numerical readings, it does not mean that we have real knowledge about our own person, whatever the proponents of the "quantified self" would say. When we really want to know the risks of disease, we must be careful to understand the data because they are influenced by statistical manipulations resulting from sets of clinical and epidemiological studies, which are sometimes difficult to interpret (Ioannidis et al., 2017).

In the situation where health promotion becomes a mechanical model of entry / exit, the person is more and more under technical control, meaning that he has to ingest certain amounts of proteins, carbohydrates, fats, vitamins and trace elements, to perform a series of physical exercises or a number of steps, all in order to consume calories. These applications can often be beneficial, helping to lower blood pressure, cholesterol, body weight, etc. Beyond producing a bizarre picture of daily life, in terms of diet and physical activity, which must be constantly monitored quantitatively, doctors have the opportunity, when patients fail to comply with the rules, to adjust the figures of exit through available technical means such as medication (Scherz, 2020).

This focus on quantitative risk, however, creates risks that the Aristotelian analysis of greed reveals. According to it, once a goal is set quantitatively, it automatically becomes infinite potential, so practically unattainable, because new risks always appear. Take, for example, cholesterol levels, which are directly related to the cardiovascular system. Specialists juggle its target levels, and patients are puzzled. The importance of Aristotelian thinking regarding an infinite goal becomes clearer when we discuss the possible side effects 
of drugs or complications that may occur after surgery. In fact, the totality of the risks from genes, environment, behaviour, diet, medication and interventions becomes impossible to quantify.

For example, there are health programs that aim to mass detect cancer through annual mammograms, Pap tests, prostate exams, colonoscopies, etc. It is believed that by screening and early detection, cancer can be detected at an early stage, thus avoiding many deaths. However, the more sophisticated the risk theory, the more complicated the problems become. For example, biopsies and mammograms have their risks. Moreover, cancer treatments are not benign. Chemotherapy and radiation therapy make the body vulnerable, and interventional surgery risks complications such as urinary or fecal incontinence, impotence, anatomical mutilation, stress and depression.

This way of thinking has led to the revision of the screening guidelines, reconsidering the age and the intervals at which they must be done. Of course, the discussions are controversial, making it impossible to draw definitive conclusions (Scherz, 2020).

\section{Individual risk and social risk}

Each patient examined has one or more diseases, which we must judge in an individual context, finally establishing the particularities of the case. This requires a holistic view of the body, namely bio-psycho-social and cultural, where etiopathogenic priming finds its place, which highlights pathogens and risk factors, inherited ground and its weakness, equating physiopathogeny, prevention, prediction and recovery.

The improvement of population health and the increase of longevity, observed since the twentieth century, are due not so much to individual medical treatments, but to major social and cultural changes: clean water, environmental protection, food security, poverty reduction, social protection and so on. There is not necessarily a declared conflict between the forms of individual and social risk management, but what we are interested in is achieving a balance between risk socialization and individualization.

Health policies in recent years have preferred to develop a technical medicine, reducing the human body and life only to numbers and mathematical operations, thus individualizing treatments when needed, to the detriment of public health measures (Berry, 2002). This trend is at the origin of the preventive medicine, based on individual risks and not on a wider application as public health (Aronowitz, 2015).

Moving our attention away from social risk to reducing individual risk, by using precision medicine undermines the virtue of solidarity and alleviating social suffering. This effect appears in the most important example of solidarity in medicine, "blood donation". It is known that "blood donation" develops solidarity within a small or larger community, through the repeated action of donating your blood to a loved one or even a stranger, living with the conviction that someone else, in turn, will donate blood for you then when you need it. Blood trading is free, excluding the simple market transaction, which if it existed undermines social ties and leads to the atomization of people. Over time, the idea of donating blood as a source of human solidarity has declined for several reasons: scandals due to blood contamination with HIV, HBsAg, HCV, increasing needs for such products, and transforming the market in the supply of blood and blood products. When a person is scheduled for major surgery, they will make sure that there is blood for themselves at the Transfusion Center, to avoid the risks associated with the absence of this product. In this situation, blood donation becomes an individual risk calculation (Starr, 1998).

Another obvious example is that of "stem cells" harvested from the umbilical cord. While doctors and researchers want these cells to be a resource to help patients, either directly through transplants or indirectly through medical research, a real industry encourages people to store these cells in special banks, where they can use them in case of need. In the 
vast majority of cases, the stored cells are lost, because most of the time the child in question does not need them. However, there are many people who prefer to insure against a hypothetical risk, thus giving up relying on a social resource (Waldby \& Mitchell, 2006).

The controversy surrounding vaccines may even better highlight how reducing individual risk contradicts solidarity. Although vaccinology is a science full of contradictions, research has thoroughly shown that childhood vaccinations do not pose a risk of causing autism or other such risks. An anti-vaccination movement has made some people doubt the safety of vaccines. This has led to a decline in the general level of vaccination and thus to the emergence of new outbreaks of diseases such as measles, which have been eradicated in the past. In this situation, proponents of vaccination cannot rely solely on proven vaccine safety to persuade reluctant parents to vaccinate their children, but use a second set of arguments based on solidarity. Because no vaccine is fully effective and many people cannot be vaccinated, preventing outbreaks requires effective immunity. In this case, a certain percentage of the population must be vaccinated to ensure that the transmission of the disease is stopped. Seen in this way, vaccination appears as a social protection project, which means that it is necessary to vaccinate children whose parents accept this method of prophylaxis, the beneficiaries being, in addition to those concerned, those who cannot be vaccinated or refuse vaccination. While some talk about solidarity, being convinced by the arguments presented, many parents consider that they are responsible only for the health of their children, making their own risk calculation. This focus on individual risk can undermine social solidarity (Shoenfeld et al., 2016).

\section{Conclusions}

1. In the contemporary cultural project, we witness the attempt to control suffering and postpone death as much as possible through science.

2. Health policies in recent years have preferred to develop a technical medicine, reducing the human body and life only to numbers and mathematical operations thus individualizing treatments when needed, to the detriment of public health measures.

3. The emergence of an alliance between politics, basic research and the pharmaceutical industry transfers health issues to the business world, and the issue of newness and efficiency in medicine must be viewed with caution and circumspection.

\section{References:}

Buta, M.G. (2008). Perspectiva bioeticii asupra sfințeniei și/sau a calității vieții. Bioethica, 2, 81-89.

Droge, M. (2016). What is the qualified self? Quantified Self Institute. http://qsinstitute.com/about/what-is-quantified-self/

Davis, J. E. \& Gonzalez, A.M. (2016). Reductionist Medicine and Its Cultural Autority. In To Fix or to Heal: Patient Carre, Patient Health and the Limits of Biomedicine (pp. 33-62). New York: NYU Press.

Heidegger, M. (1977). The Question Concerning Technology. In The Question Concerning Technology \& other Essays, Translated by William Lovitt, New York: Harper Torch Books.

Bishop J. (2011). The Anticipatory Corpse: Medicine, Power and the Care of the Dying. Notre Dame: University of Notre Dame Press

Ioannidis, J. P., Stuart, M. E., Brownlee, S. \& Strite, S.A. (2017). How to survive the medical misinformation mess. European Journal of Clinical Investigation, 47(11), 795-802.

Scherz, P. (2020). Risk, Health, and Physical Enhancement: The Dangers of Health Care as Risk Reduction for Christian Bioethics. Christian bioethics: Non-Ecumenical Studies in Medical Morality, 26(2), 145-162. 
Berry, W. (2002). Health is membership. In Wirzba, N. (Ed.). The art of Common-Place. The Agrarian Essays of Wendell Berry (pp. 144-158), Washington, DC: Countempoint

Aronowitz, R. (2015). Risky Medicine. Chicago: University of Chicago Press.

Starr, D. (1998). Blood: An Epic History of Medicine and Commerce. New York: Alfred A. Knopf.

Waldby, C. \& Mitchell, R. (2006). Tissue Economies. Durham. NC: Duke University Press.

Shoenfeld, Y., Agmon-Levin, N. \& Tomljenovic, L. (2016). Vaccines and autoimmunity. Bucharest: Cristiana.

\footnotetext{
Notes

${ }^{1}$ Wired is an American monthly magazine on the impact that emerging technologies can have on culture, economics, and politics.

${ }^{2}$ diaríst s. m. [din it. diarista; cf. fr. diariste - Le Monde ] Person who writes down in his notebook everyday events $\diamond$ There is a problem with this type of old fashioned diary, because it records a person's mood only when he is willing to do so, which can lead to errors. Basically, it is difficult to correctly follow our own subjective states, because they are influenced by many factors. However, scientists have reported since 1983, psychological studies in this direction - see Jeylan T. Mortimer, Reed W. Larson, 2012, The Changing Adolescent Experience: Societal Trends and the Transition to Adulthood, Edit. Jeylan T. Mortimer University of Minnesota, Reed W. Larson University of Urbana-Champaign, Cambridge University Press
} 